\title{
Crescimento e produção de coqueiro Anão verde fertigado com nitrogênio e potássio
}

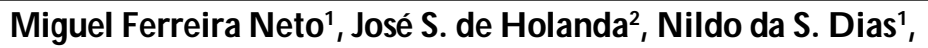 \\ Hans R. G heyi ${ }^{3} \&$ Marcos V. Folegatti ${ }^{4}$
}

\begin{abstract}
RESUMO
Tal como ocorre em outras culturas, no cultivo de coco irrigado a utilização da técnica da fertigação também tende a aumentar. O bjetivou-se com este trabalho estudar os efeitos de doses de $\mathrm{N}$ e $\mathrm{K}_{2} \mathrm{O}$ via fertigação no desenvolvimento vegetativo e na produção do coqueiro Anão verde. 0 ensaio foi conduzido no período de abril de 2002 a março de 2004, em campo experimental da Empresa de Pesquisa Agropecuária do Rio Grande do N orte - EM PARN, em Parnamirim, RN. 0 delineamento estatístico adotado foi em blocos inteiramente casualizados, com 4 repetições utilizando-se, para composição dos tratamentos, a matriz experimental Plan Puebla III, compostos da combinação de dois fatores: doses de nitrogênio e de potássio aplicados nas formas de uréia e cloreto de potássio, respectivamente, obtendo-se 10 tratamentos, definindo-se 0 intervalo para as doses de N (256 a $4874 \mathrm{~g} \mathrm{planta}^{-1} \mathrm{ano}^{-1}$ ) e K $\mathrm{O}$ (258 a $4872 \mathrm{~g}$ planta- ano $^{-1}$ ) aplicados via fertigação. 0 número de folhas, diâmetro de copa, altura e circunferência do estipe, foram favorecidos pela aplicação de $\mathrm{N}_{\text {e K}} \mathrm{O}$, em que as doses $2910 \mathrm{~g} \mathrm{planta-}^{-1}$ ano-1 $^{-1}$ de $\mathrm{K}_{2} \mathrm{O}$ e $2353 \mathrm{~g} \mathrm{planta}^{-1}$ ano-1 de $\mathrm{N}$, representaram maiores produçôes no $6^{\circ}$ ano de cultivo e no $7^{\circ}$ ano as doses de $1540 \mathrm{~g} \mathrm{planta}^{-1}$ ano $^{-1}$ de $\mathrm{K}_{2} \mathrm{O}$ e $1539 \mathrm{~g} \mathrm{planta}^{-1}$ ano $^{-1}$ de N, representaram maiores produções.
\end{abstract}

Palavras-chave: Cocos nucifera L., manejo da fertigação, nutrição de plantas

\section{Growth and yield of Anão Verde coconut under fertigation with nitrogen and potassium}

\begin{abstract}
In irrigated coconut, similar to trend in other crops the use of technique of fertigation is increasing. The objective of this study was to evaluate the effect of $\mathrm{N}$ and $\mathrm{K}_{2} \mathrm{O}$ doses under fertigation in development and the production of Anão Verde coconut palm. In April of 2002 until March of 2004, an experiment was carried out at the Empresa de Pesquisa Agropecuária do Estado do Rio Grande do Norte, Brazil. The adopted statistical design was in randomized blocks, with 4 repetitions, using for composition of treatments Puebla Plan III experimental matrix, consisting of combination of two factors: nitrogen and potassium doses in the form of urea and potassium chloride, respectively, testing 10 treatments. The interval of $\mathrm{N}$ being 256 the $4874 \mathrm{~g} \mathrm{plant}^{-1}$ year ${ }^{-1}$ and 258 to $4872 \mathrm{~g} \mathrm{plant}^{-1}$ year ${ }^{-1}$ of $\mathrm{K}_{2} \mathrm{O}$ applied through fertigation. The number of leaves, diameter of canopy, height and circumference of estipe were favored with $2910 \mathrm{~g}$ plant $^{-1}$ year ${ }^{-1}$ of $\mathrm{K}_{2} \mathrm{O}$ and $2353 \mathrm{~g} \mathrm{plant}^{1}$ year ${ }^{-1}$ of $\mathrm{N}$ representing highest productions in $6^{\text {th }}$ year of crop. In the $7^{\text {th }}$ year the dose of 1540 and $1539 \mathrm{~g} \mathrm{plant}^{1}$ year $^{1}$ of $\mathrm{K}_{2} \mathrm{O}$ e N , respectively promoted maximum productions.
\end{abstract}

Key words: Cocos nucifera L., management fertigation, plant nutrition

\footnotetext{
DCA/U FERSA, BR 110 do km 47, Bairro: Costa e Silva, CEP 59625-900, Mossoró, RN. Fone: (84) 3312-1799. E-mail: miguel@ufersa.edu.br e nildo@ufersa.edu.br

EM PARN/EM BRAPA, CP 59, CEP 59020-390, Natal, RN. Fone: (84) 3221-2301. E-mail: simplicioemparn@rn.gov.br

3 UAEA/U FCG, CP 10 056, CEP 58109-930, Campina Grande, PB. Fone: (83) 3310-1056. E-mail: hans@deag.ufcg.edu.br

ESALQ/U SP, CP 9, CEP 13418-900, Piracicaba, SP. Fone: (19) 3429-4217. E-mail: mvfolega@esalq.usp.br
} 


\section{INTRODUÇÃO}

O Brasil é o maior produtor mundial de coco verde para consumo de água do fruto e o Nordeste contribui com cerca de $85,6 \%$ da produção nacional da cultura, com área plantada de aproximadamente 280.835 ha (IBGE, 2004). Nos plantios comerciais de coqueiro no Brasil para fins de consumo in natura, predomina a variedade Anã verde, devido à sua boa performance em termos de rendimento e qualidade da água de coco, cuja produção está associada às condições de clima, recursos hídricos e solo. A expansão da industrialização reflete, ainda, o grande aumento da produção do coco-anão, variedade específica para a produção de água, consolidada como uma das mais importantes frutícolas permanentes cultivadas.

Embora o coco Anão irrigado venha aumentando sua participação na cocoicultura brasileira, os rendimentos médios esperados para cultivo irrigado dessa variedade nos $6^{\circ}$ e $7^{\circ}$ anos de cultivo ficam em torno de 32 e 54 frutos planta ${ }^{-1}$ ano $^{-1}$, respectivamente. As causas na redução de produtividade são a idade de cultivo, a baixa fertilidade dos solos, o déficit hídrico proporcionado pelo manejo inadequado da irrigação e a incidência de pragas e doenças.

Em cultivo de sequeiro ou irrigado, a fertigação é uma das práticas de expressivo impacto na produtividade do coqueiro, pois o estado nutricional do coqueiro influi no seu desenvolvimento vegetativo e, consequentemente, no número de frutos produzidos e na qualidade da água (Teixeira et al., 2003), sendo o equilíbrio nutricional essencial para se obter uma elevada e sustentável produtividade (Reddy et al., 2002).

A maioria dos estudos envolvendo necessidades de adubação do coqueiro foi realizada em condições edafoclimáticas da Ásia e especifica a variedade gigante, sendo bastante comum a utilização direta dessas recomendações tradicionais de adubação para a fertigação do coqueiro. Em razão deste empirismo, que tem frustrado muitos agricultores, diversos pesquisadores se dedicam a estudar um programa de manejo adequado da fertigação, tornando-se necessário o conhecimento dos solos, nos quais está implantada a cultura e se vislumbram aspectos básicos de nutrição, como: a remoção, a função e os sintomas de deficiência dos nutrientes.

$\mathrm{O}$ alerta de diminuição quanto à produtividade de coco proporcionada por fator nutricional procede, pois menos de $1 \%$ das plantações de coco do mundo recebe fertilizantes (Rosa et al., 2006), apesar dos resultados de experimentos importantes, bastante convincentes quanto ao aumento da produção, demonstrando haver retorno econômico com o uso da adubação.

No Brasil, as pesquisas com fertigação para o coqueiro variedade Anão verde são recentes, não dispondo de resultados consistentes que viabilizem um programa de ampla difusão entre os produtores. Visando atender satisfatoriamente às exigências nutricionais da cultura do coqueiro e ao fornecimento de nutrientes em proporções adequada objetivou-se com este trabalho avaliar os efeitos de doses de $\mathrm{N}_{\text {e }} \mathrm{K}_{2} \mathrm{O}$ via fertigação no desenvolvimento e na produção do coqueiro Anão cv. Jiqui Verde, determinando doses ótimas e econômicas de nitrogênio e potássio adequadas para a cultura no $6^{\circ}$ e $7^{\circ}$ ano de produção.

\section{Material E MÉTODOS}

O experimento foi realizado no período de abril de 2002 a março de 2004, no Campo Experimental do Jiqui, pertencente à Empresa de Pesquisa Agropecuária do Rio Grande do Norte (EMPARN), localizado no município de Parnamirim, RN (5 ${ }^{\circ} 46^{\prime}$ de Latitude Sul e $35^{\circ} 12^{\prime}$ de Longitude Oeste a $18 \mathrm{~m}$ ). Segundo a classificação de Köppen, o clima da região é do tipo As', ou seja, tropical chuvoso com verão seco e estação chuvosa adiantando-se para o outono, temperatura média anual de 28 ${ }^{\circ} \mathrm{C}$ e precipitação média anual variando de $1500 \mathrm{a} 1800 \mathrm{~mm}$.

O delineamento estatístico adotado foi o de blocos inteiramente casualizados, com 4 repetições, utilizando-se, para composição dos tratamentos, a matriz experimental Plan Puebla III, compostos da combinação de dois fatores; doses de nitrogênio $(\mathrm{N})$ e potássio $\left(\mathrm{K}_{2} \mathrm{O}\right)$ via fertigação aplicados nas formas de uréia e cloreto de potássio, respectivamente, obtendo-se 10 tratamentos (Tabela 1).

Tabela 1. Relação de tratamentos e respectivas doses de nitrogênio e potássio, aplicadas por ano via fertigação

\begin{tabular}{|c|c|c|c|c|c|c|}
\hline \multirow{3}{*}{ Trat. } & \multirow{2}{*}{\multicolumn{2}{|c|}{ Níveis }} & \multicolumn{4}{|c|}{ Doses } \\
\hline & & & $\mathbf{N}$ & $\mathrm{K}_{2} \mathrm{O}$ & Uréia & $\mathrm{KCl}$ \\
\hline & $\mathbf{N}$ & $\mathrm{K}_{2} \mathrm{O}$ & \multicolumn{4}{|c|}{ g planta $^{-1}$ ano $^{-1}$} \\
\hline 1 & $-0,4$ & $-0,4$ & 1540 & 1539 & 3420 & 2565 \\
\hline 2 & $-0,4$ & 0,4 & 1540 & 3591 & 3420 & 5985 \\
\hline 3 & 0,4 & $-0,4$ & 3591 & 1539 & 7980 & 2565 \\
\hline 4 & 0,4 & 0,4 & 3591 & 3591 & 7980 & 5985 \\
\hline 5 & $-0,9$ & $-0,4$ & 256 & 1539 & 570 & 2565 \\
\hline 6 & 0,9 & 0,4 & 4874 & 3591 & 10830 & 5985 \\
\hline 7 & $-0,4$ & $-0,9$ & 1540 & 258 & 3420 & 430 \\
\hline 8 & 0,4 & 0,9 & 3591 & 4872 & 7890 & 8120 \\
\hline 9* & 0,0 & 0,0 & 2565 & 2565 & 5700 & 4275 \\
\hline 10 & $-0,9$ & $-0,9$ & 256 & 258 & 570 & 430 \\
\hline
\end{tabular}

O pomar foi implantado em um espaçamento triangular de 7,5 m em solo dos Tabuleiros Costeiros, classificado como Neossolo Quartzarênico. Amostras do solo foram coletadas na camada de 0-20 cm para análise química: $\mathrm{pH} 5,9$; cálcio, magnésio e alumínio trocáveis, respectivamente de 0,$67 ; 0,14$ e $0,04 \mathrm{cmol}_{c}$ $\mathrm{kg}^{-1}$, matéria orgânica de $12,8 \mathrm{~g} \mathrm{~kg}^{-1}$ e fósforo, potássio e sódio, respectivamente, de 16,15 e $13 \mathrm{mg} \mathrm{kg}^{-1}$, determinados conforme metodologias recomendadas pela EMBRAPA (1997).

A área útil experimental se compunha de 200 plantas distribuídas em aproximadamente 1,6 ha com parcelas formadas por 10 plantas, dentre as quais 5 úteis e uma bordadura externa circundando o experimento. Foram incorporados ao solo da área experimental $2 \mathrm{Mg} \mathrm{ha}^{-1}$ de calcário dolomítico e $200 \mathrm{~kg} \mathrm{ha}^{-1}$ de gesso aplicados a lanço e, a cada 6 meses, realizou-se adubação incorporando-se ao solo, na área de atuação das raízes, $60 \mathrm{~L}$ de esterco de curral, $2 \mathrm{~kg}$ de FOSMAG-464® $\left(\mathrm{P}_{2} \mathrm{O}_{5}=18,0, \mathrm{Ca}=14,0, \mathrm{Mg}=3,5, \mathrm{Zn}=0,65, \mathrm{~B}=0,15 \mathrm{e}\right.$ $\mathrm{Cu}=0,18 \%$ ), além de $300 \mathrm{~g}^{\text {planta }}{ }^{-1}$ de "FTE BR-12" (micronutrientes contendo, em \%: $\mathrm{Zn}=9,00, \mathrm{~B}=1,80, \mathrm{Cu}=0,8$, $\mathrm{Mn}=2,00, \mathrm{Fe}=3,00$ e $\mathrm{Mo}=0,10)$.

Utilizaram-se, na irrigação, microaspersores autocompensantes com vazão nominal de $53 \mathrm{~L} \mathrm{~h}^{-1}$, os quais operaram à pressão de $150 \mathrm{kPa}$, proporcionando um raio molhado de 3,0 m; cada 
planta dispunha de um emissor, perfazendo o total de 10 microaspersores por linha lateral, montados ao longo das linhas de plantio, a $50 \mathrm{~cm}$ de distância, em posição paralela ao estipe. $\mathrm{Na}$ entrada de cada parcela (linha lateral) foi colocado um registro, permitindo que os tratamentos fossem isolados para entrada de fertilizantes somente nas linhas laterais desejadas. A fertigação foi realizada com o auxílio de uma bomba centrífuga, injetora de fertilizantes e a quantidade de nutrientes foi dividida em 104 aplicações durante o experimento correspondendo às semanas de cultivo do ensaio ( 2 anos), fertigando-se diariamente dois tratamentos e se completando as 10 aplicações na área em 5 dias, ou seja, dois tratamentos por dia.

A frequência de irrigação foi diária e o volume de irrigação aplicado no coqueiro foi estimado a partir da evapotranpiração de referência (ETo) calculada pelo método de PenmanMontheith modificado (Allen et al., 1998). O valor do coeficiente de cultivo (Kc) adotado para o coqueiro foi igual a 1,0, devido ao fato das experiências realizadas na área comprovar melhor correlação climática com o uso deste valor.

Como a produção foi destinada ao consumo de água de coco, os frutos foram colhidos verdes, aproximadamente com 7 meses de formação, a partir da abertura da inflorescência. As colheitas foram realizadas em todos os meses, a partir do início do experimento com intervalo de 21 dias a partir da primeira colheita, prolongando-se por um período de 2 anos.

Observaram-se as medidas da altura do estipe do coqueiro do nível do solo, até o ponto de inserção das folhas, nas épocas chuvosa (junho de 2003) e seca (dezembro de 2003) e do perímetro do estipe, com auxílio de uma trena a 1,0 m do nível do solo em três plantas dentro de cada parcela, analisando-se a porção do estipe desenvolvido com possíveis diferenças no seu diâmetro.

A partir de medidas do diâmetro de projeção da copa sobre o solo ao meio-dia, foi medida; em três plantas úteis por repetição, a área ocupada e consequentemente se inferiu seu potencial fotossintético para cada dose de adubação, sendo esta medida utilizada também, na estimativa do potencial evaporativo da planta. Observou-se a influência da adubação no número de folhas emitidas e se realizou a contagem da quantidade de folhas por planta observando-se, para cada período amostrado, o total e a manutenção da quantidade de folhas por copa, em três plantas por repetição.

O acompanhamento sistemático de abertura de inflorescências emitidas se deu a partir do $6^{\circ}$ mês de estudo e foi feito diariamente, em três plantas por repetição, anotandose a data e se numerando a folha de origem para diferenciar a idade entre cachos. Após a identificação de abertura da inflorescência realizava-se a contagem manual do total de flores femininas. Conhecendo-se as datas de emissão, calculou-se o intervalo de tempo (dias) para emissão de inflorescência.

Sete meses após a abertura completa da inflorescência, os frutos com idade de colheita ideal para consumo da água-decoco e ainda verdes, eram colhidos em um intervalo de 21 dias; enfim se quantificaram o número e o peso médio dos frutos. Após cada colheita dois frutos representativos por parcela em cada tratamento, foram retirados, aleatoriamente, para pesagens individuais e determinação do volume de água.
Realizaram-se as análises estatísticas utilizando-se o procedimento dos modelos lineares generalizados do SAS. Os efeitos dos diferentes níveis de $\mathrm{N}_{\text {e }} \mathrm{K}_{2} \mathrm{O}$ sobre as variáveis das plantas foram avaliados por superfície de resposta e através dos métodos convencionais da análise de variância (teste F), aplicando-se o teste de regressão polinomial de segunda ordem para os casos em que ocorreu efeito significativo.

\section{RESULTADOS E DISCUSSÃO}

\section{Variáveis de crescimento}

A altura do estipe não sofreu influência das doses de $\mathrm{N}$ nem da interação $\mathrm{N}$ e $\mathrm{K}_{2} \mathrm{O}$, porém as doses de $\mathrm{K}_{2} \mathrm{O}$ exerceram efeito significativo ( $\mathrm{p} \leq 0,10)$, verificando-se, então, um comportamento quadrático da altura média de estipe em função das doses de $\mathrm{K}_{2} \mathrm{O}$ aplicadas ao ano para os períodos chuvoso e de estiagem (Figura 1A). A idade das plantas é a mesma para todo o pomar; portanto, as condições edafoclimáticas interagiram com os tratamentos, de forma a pronunciar

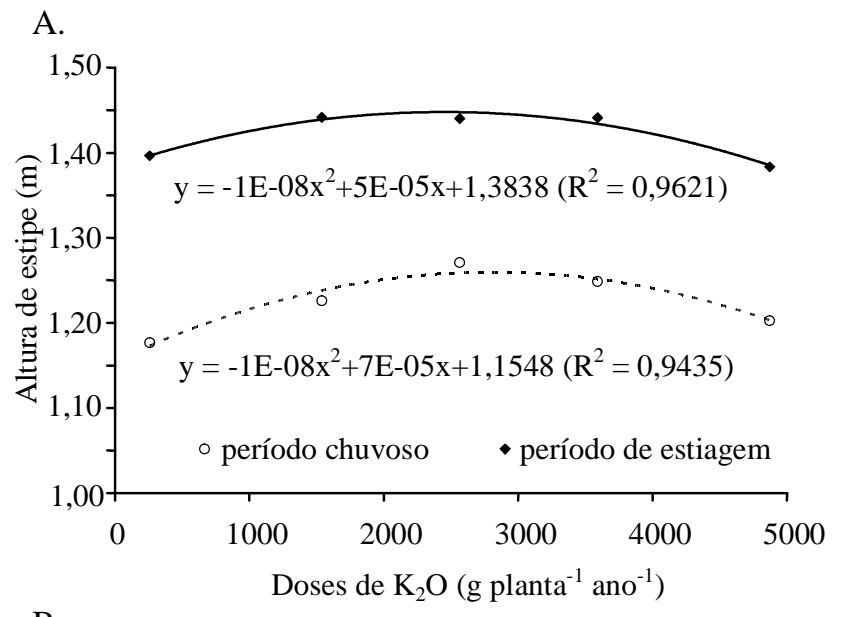

B.

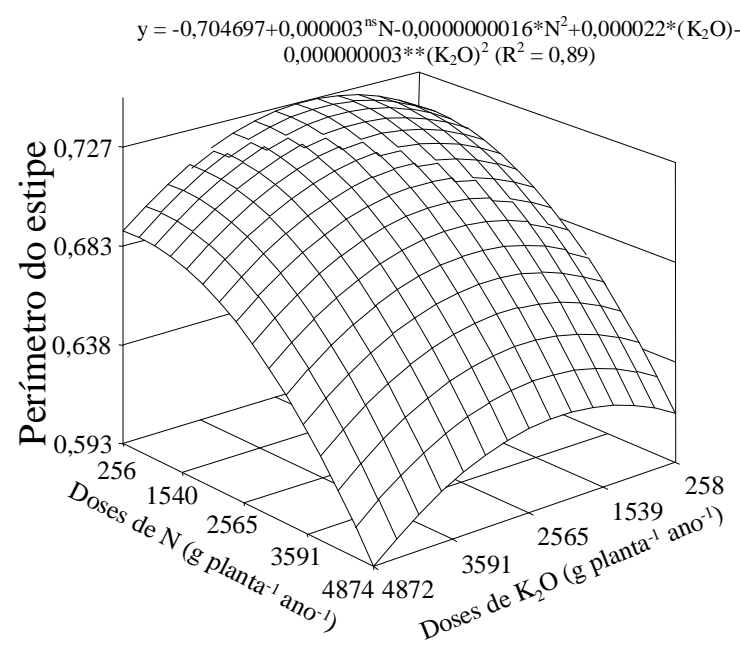

Figura 1. Altura do estipe de plantas de coqueiro Anão durante o período chuvoso (junho de 2003) e de estiagem (dezembro de 2003) em função de doses de $\mathrm{K}_{2} \mathrm{O}(\mathrm{A})$ e a superfície de resposta do perímetro do estipe com doses de $\mathrm{N} \mathrm{e} \mathrm{K}_{2} \mathrm{O}(\mathrm{B})$ 
diferenças de altura de estipe no período de estiagem, repercutindo nas plantas, em resposta ao período chuvoso.

Observa-se ainda que houve um crescimento maior $(0,22 \mathrm{~m})$ do estipe até 2565 g planta $^{-1}$ ano $^{-1}$ de $_{2} \mathrm{O}$ (Figura 1A), fato que se explica em virtude do período chuvoso ter favorecido o desenvolvimento naqueles tratamentos, o que se constata no período de estiagem; já, o perímetro do estipe sofreu efeito significativo das doses de $\mathrm{N}(\mathrm{p} \leq 0,05)$ e $\mathrm{K}_{2} \mathrm{O}(\mathrm{p} \leq 0,01)$ sem que fosse constatada interação entre elas (Figura 1B).

De acordo com a Figura 1B, observa-se que as doses de $\mathrm{K}_{2} \mathrm{O}$ promoveram efeito no aumento do perímetro de estipe, $\mathrm{o}$ que não ocorreu em relação às doses de $\mathrm{N}$, fato este comprovado pela maior curvatura e descendência da linha da variável 'doses de N', que o perímetro do estipe foi menor quando se elevaram as doses de $\mathrm{N}$ na fertigação. Quanto a fertigação com $\mathrm{K}_{2} \mathrm{O}$, a dose que promoveu maior diâmetro de estipe $(0,73 \mathrm{~m})$ foi de $2180 \mathrm{~g} \mathrm{planta}^{-1} \mathrm{ano}^{-1}$.

Em condições de seca prolongada, a má nutrição ou ataque de pragas e doenças, a porção do estipe desenvolvida neste período pode apresentar variações no seu diâmetro, reduzindoo em decorrência de variações no tamanho individual das células (Child, 1974). O coqueiro Anão cv. verde do Jiqui se tem destacado quanto ao melhor desempenho deste atributo dentre os demais cultivares da variedade Anão (Ramos et al., 2004).

Nos períodos de estudo, houve variações quanto ao número de folhas vivas, em todos os tratamentos analisados; entretanto no período chuvoso as plantas apresentaram menor quantidade média de folhas em relação ao período de estiagem, com uma diferença média em torno de 7 folhas de um período a outro, o que se deve, possivelmente, à maior umidade relativa do período, ao retardar a emissão das folhas. Leite \& Encarnação (2002) contrastam com o presente trabalho, pois não encontraram diferenças entre os períodos de chuva e de estiagem quanto ao número de folhas mortas e durante o período chuvoso a emissão de folhas foi mais frequênte.

$\mathrm{Na}$ avaliação do número de folhas vivas no período chuvoso, encontrou-se efeito quadrático (Figura 2A) significativo $(\mathrm{p} \leq 0,10)$ para o $\mathrm{K}_{2} \mathrm{O}$, revelando tendência de aumento desta variável vegetativa; porém, quando se avaliou esta variável de crescimento na época de estiagem, constatouse efeito quadrático e significativo $(\mathrm{p} \leq 0,05)$ das doses de $\mathrm{N}$, tendo pequeno acréscimo na quantidade de folhas, fato comprovado pela constância da superfície de resposta (Figura 2B) das doses de $\mathrm{K}_{2} \mathrm{O}$ em condições de baixa dose de N. Silva et al. (2009) constataram, em experimento conduzido na mesma área experimental do presente estudo, que apenas o $\mathrm{N}$ provocou aumento da emissão de folhas do coqueiro Anão verde, visto que o número de folhas emitidas cresceu de 21,15 com a dose de $135 \mathrm{~g}$ planta $^{-1}$ ano $^{-1}$ de $\mathrm{N}$ para 22,76 com a dose de $2565 \mathrm{~g}$ planta $^{-1}$ ano $^{-1}$ de N.

Quando há um incremento conjunto das doses de $\mathrm{N}$ e $\mathrm{K}_{2} \mathrm{O}$ na fertigação do coqueiro há, também, um favorecimento quanto ao aumento do número de folhas vivas. Ainda com relação a esta época, a dose de $\mathrm{N}$ com maior representatividade no número de folhas vivas é $2565 \mathrm{~g}_{\text {planta }}{ }^{-1} \mathrm{ano}^{-1}$; portanto, o ambiente desempenhou papel significativo de condicionador, no comportamento vegetativo da cultura evidenciando que a emissão foliar pode variar com a época do ano.

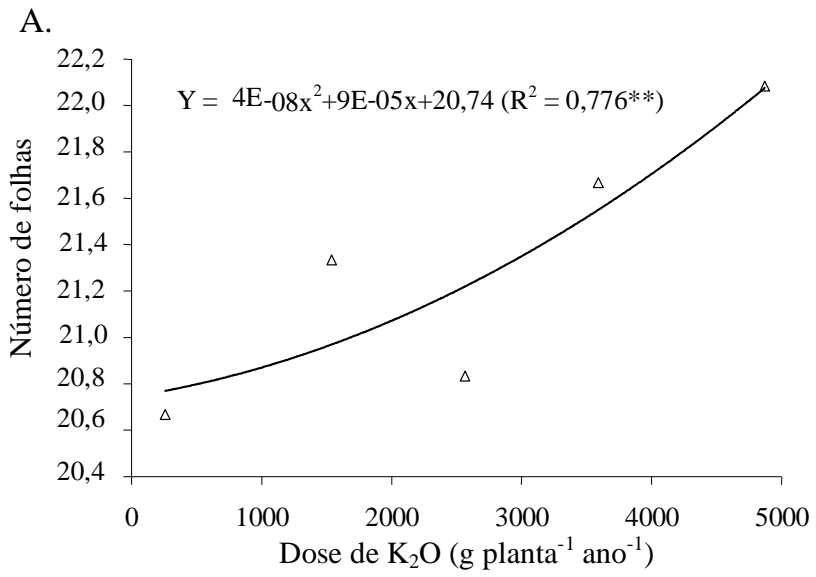

B.

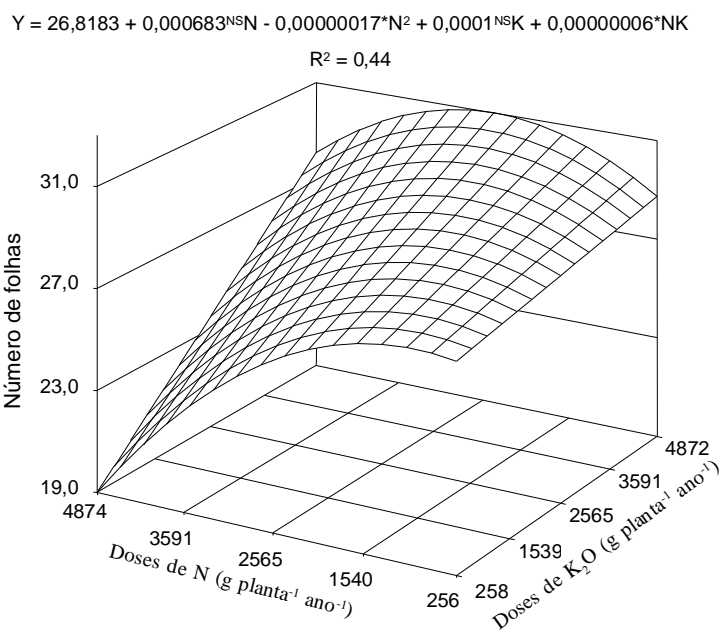

Figura 2. Número de folhas vivas de coqueiro Anão por planta durante o período chuvoso (junho de 2003) em função de doses de $K_{2} O(A)$ e superfície de resposta do período de estiagem (dezembro de 2003) em função de doses de $\mathrm{K}_{2} \mathrm{O}$ e $\mathrm{N}(\mathrm{B})$

Ferreira Neto et al. (2007), trabalhando sob as mesmas condições climáticas e a mesma variedade de coqueiro sob condições de salinidade, contabilizaram uma emissão foliar de 16 folhas ano $^{-1}$ com número médio de 22,25 folhas planta $^{-1}$ na testemunha; já Leite \& Encarnação (2002) relatam uma emissão média de folhas para a variedade Anão de 11 folhas $a^{-1}$ e uma frequência maior de emissão, no período chuvoso.

Em cultivos irrigados, evidentemente o coqueiro Anão tem desenvolvimento favorecido na época de escassez de chuvas, indicando que, neste período, o aproveitamento do $\mathrm{N}$ adicionado foi melhor, estimulando o crescimento vegetativo. Segundo Passos (1997), uma planta adulta de coqueiro Anão sob condições ambientais favoráveis pode emitir 18 folhas por ano. Os valores médios ( 22 folhas) observados para o número de folhas em todos os tratamentos durante o período chuvoso, ficam abaixo da média de 25 a 30 folhas planta ${ }^{-1}$, mencionado por Child (1974).

Segundo Passos (1997) quando o coqueiro é cultivado sob condições de deficiência nutricional e ambiental, ocorre redução no número de folhas vivas por planta, devido provavelmente à redução no ritmo de emissão foliar e à menor duração da folha. Esta duração foi menor, provavelmente, do 
que o mencionado por Child (1974), o qual relata que as folhas permanecem vivas de 36 a 42 meses; porém, Frémond et al. (1975) discordam da afirmação de que a redução do número de folhas na copa do coqueiro, sob condições ambientais desfavoráveis, é causada pela morte precoce da folha; segundo esses autores, ela seria causada pela redução no ritmo de emissão foliar. De fato, o K não está associado ao aumento do vigor vegetativo das culturas, podendo atuar como "regulador" de crescimento, inibindo o crescimento excessivo quando a disponibilidade de $\mathrm{N}$ é alta.

Na avaliação de diâmetro de copa (Figura 3) encontraramse efeitos significativos $(\mathrm{p} \leq 0,10)$ das doses de $\mathrm{N}$ e $\mathrm{K}_{2} \mathrm{O}$ isoladamente e quando interagiram entre si, embora as doses de $\mathrm{Ne} \mathrm{K}_{2} \mathrm{O}$ isoladamente tenham pouca influência no aumento do diâmetro.

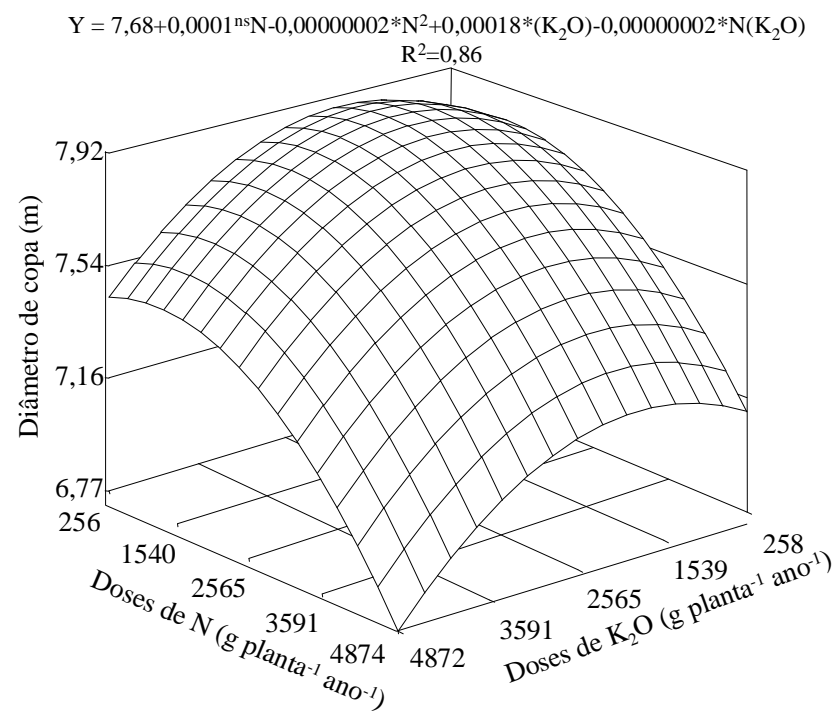

Figura 3. Superfície de resposta do diâmetro sombreado do coqueiro Anão com doses de $\mathrm{N}$ e $\mathrm{K}_{2} \mathrm{O}$

Quando esses fatores interagiram nas dosagens de $1540 \mathrm{~g}$ de $\mathrm{N}$ com $2500 \mathrm{~g}$ de $\mathrm{K}_{2} \mathrm{O}$, induziram o aumento do diâmetro de copa para aproximadamente $8 \mathrm{~m}$. A correlação da superfície de resposta evidencia que o diâmetro sombreado da área foliar foi menor com doses elevadas de $\mathrm{N}$ e $\mathrm{K}_{2} \mathrm{O}$ na fertigação. Os resultados encontrados na determinação do diâmetro sombreado da copa do coqueiro traz à tona uma nova definição do espaçamento entre plantas para a variedade Anão verde, que é recomendação do plantio em formação triangular de 7,5 $\mathrm{m}$, principalmente quando do uso das dosagens de fertigação ideais indicadas neste trabalho.

\section{Variáveis de produção}

O intervalo entre as emissões de inflorescência, no período analisado, não sofreu efeito das doses de fertigação. O coqueiro emitiu, em 9 meses, o total de 12 inflorescência representando intervalo médio entre emissões de 22 dias. Esses resultados divergem dos divulgados por Leite \& Encarnação (2002) que relatam um intervalo médio de emissão para a variedade Anã de 28 dias e afirmam que durante os períodos secos houve picos de emissão de inflorescência, podendo ser atribuído ao fotoperíodo incidente.
Aragão et al. (2001), apesar de não citarem o intervalo, constatam que a cv Anão verde do Jiqui apresenta maior precocidade dentre todas as outras variedades e híbridos. Alguns autores atribuem as variações de emissão de inflorescência ao déficit hídrico ocorrido até dois anos antes da colheita. Além disso, as variações sazonais do ritmo de emissão das inflorescências são influenciadas pelo desequilíbrio nutricional das plantas e pelo estresse osmótico quando se irriga com água salina (Marinho et al., 2005; Ferreira Neto et al., 2007).

O número de flores femininas por inflorescência do coqueiro variou em função das condições nutricionais impostas pela fertigação. Assim, o número de flores femininas apresentou efeito significativo $(\mathrm{p} \leq 0,01)$ das doses de $\mathrm{N}$ e $\mathrm{K}_{2} \mathrm{O}$ sem que fossem verificadas interações entre elas. Observa-se que, à medida que se eleva a dose de $\mathrm{K}_{2} \mathrm{O}$ no solo, com redução em mesma ordem das doses de $\mathrm{N}$, o efeito é proporcional e evolutivo na quantidade de flores femininas por planta (Figura 4). As doses em torno de $2565 \mathrm{~g} \mathrm{planta}^{-1}$ ano $^{-1}$ de $\mathrm{K}_{2} \mathrm{O}$ e $1540 \mathrm{~g}$ planta $^{-1}$ ano $^{-1}$ de N, promoveram a obtenção das maiores médias para a quantidade de flores femininas por planta durante o período. $\mathrm{O}$ aumento das doses de nitrogênio no solo acima da dose mencionada anteriormente $\left(1540 \mathrm{~g} \mathrm{planta}^{-1} \mathrm{ano}^{-1}\right)$ provoca redução brusca para esta variável de produção.

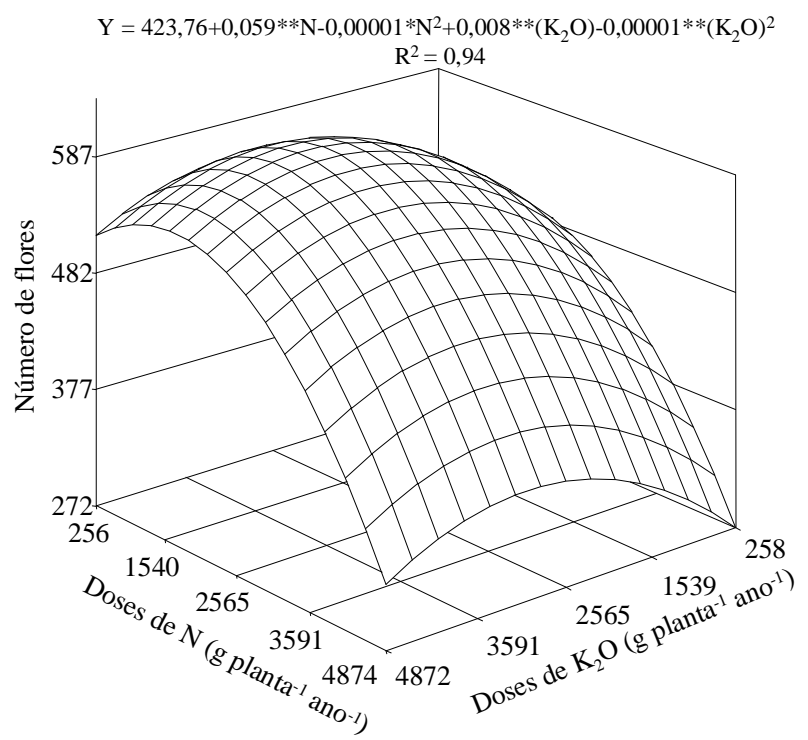

Figura 4. Superfície de resposta do número total de flores femininas do coqueiro Anão em função de doses de $\mathrm{N}_{\text {e }} \mathrm{K}_{2} \mathrm{O}$

$\mathrm{O}$ coqueiro tem alta eficiência no uso do $\mathrm{N}$ e o aumento excessivo nas dosagens de $\mathrm{N}$ proporciona redução na média satisfatória do número de flores femininas por inflorescência, fato comprovado pela maior curvatura e decréscimo da linha do fator 'doses de N' (Figura 4).

O potássio é mais reivindicado pelo coqueiro no aumento do número de flores femininas, destacando-se a importância do nutriente na produtividade da planta. O total de flores femininas por inflorescência em coqueiro da variedade Gigante varia de 20 a 40, com tendência de aumento no coqueiro da variedade Anão (FAO, 2005); fato comprovado por Ferreira Neto et al. (2002) em condições de salinidade, chegando a 
produzir aproximadamente 240 flores femininas por inflorescência, muito embora este valor não se reflita no maior número de frutos.

É mais comum cada inflorescência apresentar de 40 a 60 flores femininas sendo que o número de flores femininas é muito mais instável do que o número de flores masculinas. Frémond et al. (1975) relatam que o pequeno número de flores pode estar relacionado às condições desfavoráveis de umidade, durante os meses em que ocorre a diferenciação; para isto, o coqueiro requer condições edafoclimáticas satisfatórias visando manter sua carga produtiva, uma vez que a planta emite inflorescências continuamente, durante todo o ano, encontrado-se frutos nos diferentes estádios de desenvolvimento.

As produções do coqueiro nos $6^{\circ}$ e $7^{\circ}$ anos de cultivo sob influência das doses de $\mathrm{N}$ e $\mathrm{K}_{2} \mathrm{O}$, apresentaram médias satisfatórias com relação ao número de frutos colhidos por planta ano $^{-1}$, em virtude da média geral entre todos os tratamentos ter ficado acima de 200 frutos planta ${ }^{-1}$ ano $^{-1}$. Para uma produção comercial de coco verde sob condição de irrigação, esta produção é bastante satisfatória, ressaltandose a idade de cultivo; o número de frutos foi influenciado significativamente pelas doses de $\mathrm{N}$ apresentando efeito quadrático $(\mathrm{p} \leq 0,01)$ nos dois anos $\left(6^{\circ}\right.$ e $\left.7^{\circ}\right)$ de produção; já o efeito do potássio mostrou-se influente $(\mathrm{p} \leq 0,05)$ na quantidade de frutos planta ${ }^{-1}$ apenas no $6^{\circ}$ ano; portanto, não houve interação entre as doses de $\mathrm{N}$ e $\mathrm{K}_{2} \mathrm{O}$.

Pode-se observar, pela superfície de resposta apresentada na Figura 5A, que na medida em que se eleva a dose de $\mathrm{K}_{2} \mathrm{O}$ e $\mathrm{N}$ no solo, o efeito é revertido numa quantidade maior de frutos. A dose de 2910 g planta $^{-1}$ ano $^{-1}$ de $\mathrm{K}_{2} \mathrm{O}$ e 2353 g planta $^{-1}$ ano $^{-1}$ de $\mathrm{N}$, representa os níveis para obtenção da quantidade máxima de frutos para o $6^{\circ}$ ano de cultivo. $\mathrm{O}$ aumento das doses de nitrogênio e potássio no solo acima das mencionadas, chega a provocar redução na produção de frutos. A dose econômica na fertigação para o $6^{\circ}$ ano de produção correspondeu a $2243 \mathrm{~g}$ de $\mathrm{N}_{\text {planta }}$ ano $^{-1}$ e $2786 \mathrm{~g}$ de $\mathrm{K}_{2} \mathrm{O}$ planta $^{-1}$ ano $^{-1}$, considerandose os preços vigentes na região, $\mathrm{R} \$ 0,27$ por coco verde; $\mathrm{R} \$$ $1,67 \mathrm{~kg}^{-1} \mathrm{de} \mathrm{N}$ e R $\$ 1,45 \mathrm{~kg}^{-1}$ de $\mathrm{K}_{2} \mathrm{O}$.

No $7^{\circ}$ ano (Figura $5 \mathrm{~B}$ ) a dose de $\mathrm{N}$ com maior expressividade na produção média de frutos foi de $2300 \mathrm{~g} \mathrm{planta}^{-1} \mathrm{ano}^{-1}$ gerando 225 frutos planta $^{-1}$ quando conciliada a dose similar para o potássio; porém este aumento se deu de forma suave. A dose econômica de fertigação para o $7^{\circ}$ ano de produção correspondeu, também, a $1540 \mathrm{~kg}$ de $\mathrm{N}_{\text {planta }}{ }^{-1}$ e $1539 \mathrm{~kg}$ de $\mathrm{K}_{2} \mathrm{O}$ planta $^{-1}$; mesmo ao se considerar que não houve efeito significativo do potássio no aumento de produção deste ano.

O aumento das doses a partir daquelas de maior expressão na produção proporcionou um consumo de luxo, já que não se reflete em aumento da produção. Pelas observações realizadas neste ano, a redução na quantidade exigida de $\mathrm{N}$ pela planta na comparação entre as maiores produções pode ser explicada pela manutenção da concentração desse nutriente ao longo do período de estudo e também pela tendência de estabilização da produção que é alcançada pela planta a partir do $7^{\circ}$ ano de cultivo. Tais incrementos de produção gerados pela adição de N, divergem de pesquisas já realizadas (Jucá et al., 2002; Santos et al., 2004; Teixeira et al., 2005).
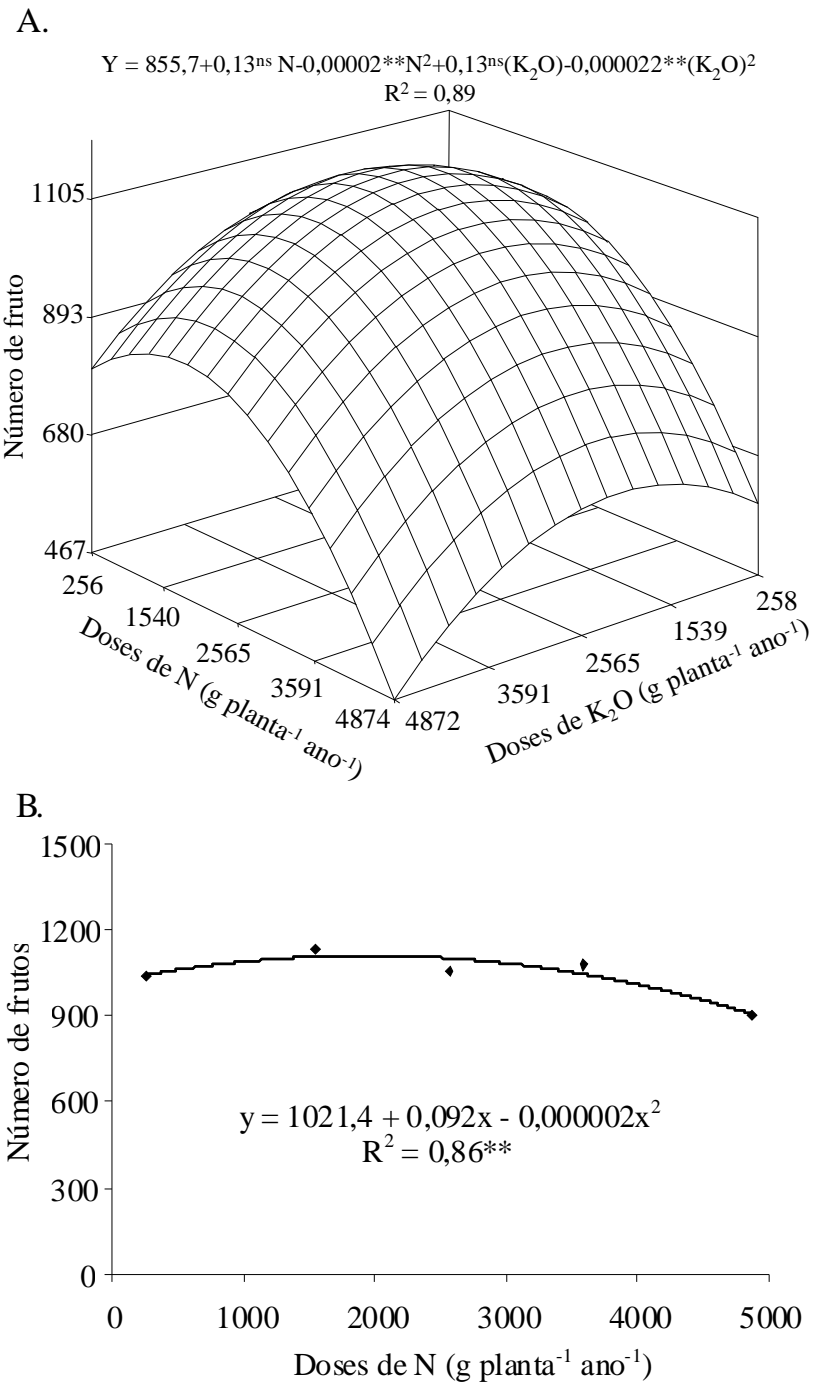

Figura 5. Superfície de resposta do número total de frutos de coqueiro Anão colhidos por parcela (5 plantas) no 60 ano de cultivo, em função de doses de $\mathrm{N}_{\text {e }} \mathrm{K}_{2} \mathrm{O}$ aplicadas $(\mathrm{A})$ e o número total de frutos colhidos por parcela (5 plantas) no 70 ano de cultivo, em função das doses de $\mathrm{N}$ aplicadas (B)

Lins et al. (2003), verificaram, trabalhando com coqueiro híbrido, em dez anos de produção, que a aplicação de nitrogênio não influenciou as variáveis de produção-número de coco por planta e peso de albúmem por fruto. No presente estudo o ambiente condiz parcialmente com o descrito pelos autores citados, de forma que a alta frequência de irrigação localizada, as capinas e o pastejo dos ovinos na área experimental, remontam a esta mesma condição. Outros fatores que se deve levar em consideração é a textura arenosa do solo, o parcelamento das doses de $\mathrm{N}$ e a sua forma de aplicação, características de cultivo que induzem ao consumo do $\mathrm{N}$ adicionado à planta, na forma de uréia.

Para IRHO (1992), em pomares de coco bem administradas com leguminosa, a cobertura do solo, implantada desde o início do cultivo, satisfaz a nutrição de nitrogênio, apesar do baixo teor de matéria orgânica e de $\mathrm{N}$ nos solos, isto porque os autores em 10 anos de pesquisa e utilizando a variedade gigante e um híbrido de coco, não observaram a influência da adubação nitrogenada no aumento da produção de coco 
planta $^{-1}$ nem na quantidade de albúmem sólido produzido. Lins et al. (2003) comprovaram esta afirmação observando que apenas a cobertura do solo com leguminosa garante tanto a proteção do solo quanto o suprimento de nitrogênio às plantas.

Azevedo et al. (2006), ao conduzirem experimentos com fertigação nas doses de $2000 \mathrm{~g}$ planta $^{-1} \mathrm{ano}^{-1}$ de $\mathrm{N}$ e $3300 \mathrm{~g}$ planta $^{-1}$ ano $^{-1}$ de $\mathrm{K}_{2} \mathrm{O}$ aplicada ao coqueiro Anão em condições ambientais semelhantes às deste trabalho, mencionam produções médias de até 270 frutos planta $^{-1}$, já a partir do terceiro ano de produção (corresponde ao $6^{\circ}$ ano de cultivo), sem haver diferenças entre os tratamentos de volume de água aplicada; mas havendo diferença entre os anos de produção; esta dosagem se situa na faixa ótima para maior produção do presente trabalho.

Diante de todos os relatos, inclusive de agricultores, não se percebe a estabilização de produtividade em relação aos picos de produção ocorridos durante os vários anos consecutivos. Este comportamento é explicado, sobretudo pela exaustão fisiológica da planta, em decorrência da extração precoce dos frutos ainda verdes, em grande quantidade. $\mathrm{O}$ coqueiro Anão, com finalidade de produção de água, não consegue completar o ciclo natural da vida, ou seja, seus frutos são retirados antes que atinjam a maturação e, nesta condição, tendem a produzir mais frutos, pois a produção de coco verde é determinada pelo mercado e não por uma condição natural da planta.

Quando Lins et al. (2003) avaliaram os efeitos da adubação potássica em relação ao coqueiro híbrido e observaram que esse nutriente exerceu efeito negativo na produção de coco nos segundo, terceiro e quinto anos de colheita, chegando a uma redução de $11,3 \%$. Os autores relatam, ainda, que o $\mathrm{KCl}$ só se tornou influente no número de coco planta $^{-1}$ a partir do sexto ano. O aumento na produção de coco planta ${ }^{-1}$, proporcionado pelo K, é confirmado por IRHO (1992) chegando a aumentar em mais de $100 \%$ quando o coqueiro gigante foi cultivado em areia litorânea.

\section{ConclusõEs}

1. O crescimento vegetativo do coqueiro é influenciado pelas doses de $\mathrm{N}$ e $\mathrm{K}_{2} \mathrm{O}$ aplicadas via fertigação, as quais quando aplicadas, exercem efeito no intervalo entre emissões de inflorescências do coqueiro Anão verde.

2. As doses de $2565 \mathrm{~g} \mathrm{planta}^{-1}$ ano $^{-1}$ de K e $1540 \mathrm{~g} \mathrm{planta}^{-1}$ ano $^{-1}$ de $\mathrm{N}$ proporcionam maiores médias na quantidade de flores femininas por planta; já o aumento excessivo nas dosagens de $\mathrm{N}$ proporciona redução na média do número de flores femininas, por inflorescência. O potássio é mais reivindicado pela planta no aumento do número de flores femininas do coqueiro.

3. A dose de 2910 g planta $^{-1}$ ano $^{-1}$ de $\mathrm{K}_{2} \mathrm{O}$ e $2353 \mathrm{~g} \mathrm{planta}^{-1}$ $\mathrm{ano}^{-1}$ de N, representa as maiores médias de produção de frutos por planta para o $6^{\circ}$ ano de cultivo; no $7^{\circ}$ ano de cultivo a dose de nitrogênio, com maior expressividade na produção média de frutos, foi de $2300 \mathrm{~g}_{\text {planta }}{ }^{-1} \mathrm{ano}^{-1}$.

\section{LITERATURA CITADA}

Allen, R. G.; Pereira, L. S.; Raes, D.; Smith, M. Crop evapotranspiration: Guide for computing crop water requirements. Rome: FAO, 1998. 300p.

Aragão, W. M.; Cruz, E. M. O.; Helvécio, J. S. Caracterização morfológica do fruto e química da água de coco em cultivares de coqueiro Anão (Cocos nucifera L. var. Nana). Revista Agrotrópica, v.13, p.56-70, 2001.

Azevedo, B. M.; Bezerra, J. W. T.; Freitas, J. A. D.; Viana, T. V. A. Efeito da frequência de irrigação na qualidade de frutos do coqueiro Anão. Irriga, v.11, p.280-292, 2006.

Child, R. Coconut. London: Longman, 1974. 335p.

EMBRAPA - Empresa Brasileira de Pesquisa Agropecuária. Manual de métodos de análise de solo. 2.ed. Rio de Janeiro: Embrapa CNPS, 1997. 212p. Documentos, 1.

FAO - Food and Agriculture Organization. http://apps.fao.org consultado. 10 Jan. 2005.

Ferreira Neto, M. Gheyi, H. R.; Fernandes, P. D.; Holanda, J. S. de; Blanco, F. F. Emissão foliar, relações iônicas e produção do coqueiro irrigado com água salina. Ciência Rural, v.37, p.1675-1681, 2007.

Ferreira Neto, M.; Gheyi, H. R.; Holanda, J. S. de; Medeiros, J. F. de.; Fernandes, P. D. Qualidade do fruto verde de coqueiro em função da irrigação com água salina. Revista Brasileira de Engenharia Agrícola e Ambiental, v.6, p.69-75. 2002.

Fremond. Y.; Ziller, R.; Lamothe, M. N. El Cocotero. Barcelona: Blume, 1975. 236p. Coleccion Agricultura tropical

IBGE - Instituto Brasileiro de Geografia e Estatística. Anuário estatístico do Brasil. Rio de Janeiro: IBGE, v.64. 2004.

IRHO - Institut de Recherche pour Les Huiles et Oleagineux. Coconut: Water supply and drought tolerance. Oléagineux, v.47, p.334-337, 1992.

Jucá, M. P.; Gaíva, H. N.; Pereira, W. E.; Mileski, A. Comportamento vegetativo de seis cultivares de coqueiroanão (Cocos nucifera L.), em Santo Antônio de Leverger MT. Revista Brasileira de Fruticultura, v.24, p.463-467, 2002.

Leite, I. R. do M.; Encarnação, C. R. F. da. Fenologia do coqueiro na zona costeira de Pernambuco. Pesquisa Agropecuária Brasileira, v.37, p.745-752, 2002.

Lins, P. M. P.; Farias Neto, J. T.; Muller, A. A. Avaliação de híbridos de coqueiro (Cocus nucifera L.) para produção de frutos e de albúmen fresco. Revista Brasileira de Fruticultura, v.25, p.468-470, 2003.

Marinho, F. J. L.; Gheyi, H. R.; Fernandes, P. D. Germinação e formação de mudas de coqueiro irrigadas com águas salinas. Revista Brasileira de Engenharia Agrícola Ambiental, v.9, p.334-340, 2005.

Passos, E. E. M. Ecofisiologia do coqueiro. In: Ferreira, J. M. S.; Warwick, D. R. N.; Siqueira, L. A. (ed.) A cultura do coqueiro no Brasil. Aracaju: Embrapa SPI, 1997. p.65-72.

Ramos, V. H. V.; Pinto, A. C. de Q.; Aragão, W. M.; Gomes, A. C.; Junqueira, N. T. V.; Lobato, E.; Oliveira, M. A. S. Comportamento de cultivares de coqueiro anão e híbridos no Distrito Federal. Revista Brasileira de Fruticultura, v.26, p.363-365, 2004. 
Reddy, D. V. S.; Upadhyay, A. K.; Gopalasundaram, P. H.; Khan, $\mathrm{H}$. Response of high yielding coconut variety and hybrids to fertilization under rainfed and irrigated conditions. Nutrient Cycling in Agroecosystems, v.62, p.131-138, 2002.

Rosa, R. C. C.; Monnerat, P. H.; Santos, A. L. dos; Pires, A. A.; Pinho, L. G da R.; Martins, A. O. Doses de nitrogênio e potássio em fertirrigação em maracujazeiro amarelo consorciado com coqueiro-anão verde, na região norte fluminense. Revista Brasileira de Fruticultura, v.28, p.113-116, 2006.

Santos, A. L. dos; Monnerat, P. H.; Carvalho, A. J. C. de. Estabelecimento de normas DRIS para o diagnóstico nutricional do coqueiro Anão Verde na Região Norte Fluminense. Revista Brasileira de Fruticultura, v.26, p.330-334, 2004.
Silva, R. A; Cavalcante, L. F.; Holanda, J. S.; Paes, R. A.; Madalena, J. A. S. Crescimento e produção do coqueiro anão verde fertirrigado com nitrogênio e potássio. Caatinga, v.22, p.161-167, 2009.

Teixeira, L. A. J.; Bataglia, O. C.; Buzetti, S.; Furlani Júnior, E.; Isepon, J. S. Adubação com NPK em coqueiro anão-verde (Cocos nucifera L.) - Rendimento e qualidade de frutos. Revista Brasileira de Fruticultura, v.27, p.120-123, 2005.

Teixeira, L. A. J.; Ruggiero, C.; Natale, W. Alterações de alguns atributos químicos do solo decorrentes da irrigação e adubação nitrogenada e potássica em bananeira após dois ciclos de cultivo. Revista Brasileira de Fruticultura, v.23, p.684-689, 2003. 